Louisiana State University

LSU Digital Commons

4-23-2012

\title{
The role of Ni-Mn hybridization on the martensitic phase transitions in Mn-rich Heusler alloys
}

Mahmud Khan

University of Alberta

J. Jung

University of Alberta

S. S. Stoyko

University of Alberta

Arthur Mar

University of Alberta

Abdiel Quetz

Southern Illinois University Carbondale

See next page for additional authors

Follow this and additional works at: https://digitalcommons.Isu.edu/physics_astronomy_pubs

\section{Recommended Citation}

Khan, M., Jung, J., Stoyko, S., Mar, A., Quetz, A., Samanta, T., Dubenko, I., Ali, N., Stadler, S., \& Chow, K. (2012). The role of Ni-Mn hybridization on the martensitic phase transitions in Mn-rich Heusler alloys. Applied Physics Letters, 100 (17) https://doi.org/10.1063/1.4705422 


\section{Authors}

Mahmud Khan, J. Jung, S. S. Stoyko, Arthur Mar, Abdiel Quetz, Tapas Samanta, Igor Dubenko, Naushad Ali, Shane Stadler, and K. H. Chow 


\section{Southern Illinois University Carbondale OpenSIUC}

\section{The Role of Ni-Mn Hybridization on the Martensitic Phase Transitions in Mn-rich Heusler Alloys}

Mahmud Khan

University of Alberta

J.Jung

University of Alberta

S. S. Stoyko

University of Alberta

Arthur Mar

University of Alberta

Abdiel Quetz

Southern Illinois University Carbondale

See next page for additional authors

Follow this and additional works at: http://opensiuc.lib.siu.edu/phys_pubs

(C) 2012 American Institute of Physics

Published in Applied Physics Letters, Vol. 100 No. 17 (2012) at doi: 10.1063/1.4705422

\section{Recommended Citation}

Khan, Mahmud, Jung, J., Stoyko, S. S., Mar, Arthur, Quetz, Abdiel, Samanta, Tampas, Dubenko, Igor, Ali, Naushad, Stadler, Shane and Chow, K. H. "The Role of Ni-Mn Hybridization on the Martensitic Phase Transitions in Mn-rich Heusler Alloys." (Apr 2012).

This Article is brought to you for free and open access by the Department of Physics at OpenSIUC. It has been accepted for inclusion in Publications by an authorized administrator of OpenSIUC. For more information, please contact opensiuc@lib.siu.edu. 
Authors

Mahmud Khan, J. Jung, S. S. Stoyko, Arthur Mar, Abdiel Quetz, Tampas Samanta, Igor Dubenko, Naushad Ali, Shane Stadler, and K. H. Chow 


\title{
The role of $\mathrm{Ni}-\mathrm{Mn}$ hybridization on the martensitic phase transitions in Mn-rich Heusler alloys
}

\author{
Mahmud Khan, ${ }^{1}$ J. Jung, ${ }^{1}$ S. S. Stoyko, ${ }^{2}$ Arthur Mar, ${ }^{2}$ Abdiel Quetz, ${ }^{3}$ Tapas Samanta, ${ }^{3}$ \\ Igor Dubenko, ${ }^{3}$ Naushad Ali, ${ }^{3}$ Shane Stadler, ${ }^{4}$ and K. H. Chow ${ }^{1}$ \\ ${ }^{1}$ Department of Physics University of Alberta, Edmonton, Alberta T6G 2E1, Canada \\ ${ }^{2}$ Department of Chemistry, University of Alberta, Edmonton, Alberta T6G 2G2, Canada \\ ${ }^{3}$ Department of Physics, Southern Illinois University Carbondale, Carbondale, Illinois 62901, USA \\ ${ }^{4}$ Department of Physics and Astronomy, Louisiana State University, Baton Rouge, Louisiana 70803, USA
}

(Received 21 March 2012; accepted 7 April 2012; published online 23 April 2012)

\begin{abstract}
Room temperature $\mathrm{x}$-ray diffraction, dc magnetization, and ac susceptibility measurements have been performed on a series of $\mathrm{Mn}$ rich $\mathrm{Ni}_{50} \mathrm{Mn}_{37-x} \mathrm{Cr}_{x} \mathrm{Sb}_{13}$ and $\mathrm{Ni}_{50+x} \mathrm{Mn}_{37-x} \mathrm{Sb}_{13}$ Heusler alloys. Depending on the value of $x$, the room temperature crystal structures of the samples are either $\mathrm{L} 2_{1}$ cubic or orthorhombic. It is a commonly accepted idea that the martensitic transition temperatures in Ni-Mn-Z (Z $=\mathrm{Ga}$, In, Sb, Sn) based Heusler alloys decrease (increase) with decreasing (increasing) valence electron concentration, ela. However, the present work shows that regardless of the change in $e / a$, the martensitic transition temperature $\left(\mathrm{T}_{M}\right)$ decreases with increasing $\mathrm{Cr}$ or $\mathrm{Ni}$ concentration. These results support the model where, in the case of $\mathrm{Mn}$ rich Heusler alloys, it is the hybridization between the $\mathrm{Ni}$ atoms and the $\mathrm{Mn}$ atoms in the $\mathrm{Z}$ sites that plays the dominant role in driving the martensitic transformation. (C) 2012 American Institute of Physics. [http://dx.doi.org/10.1063/1.4705422]
\end{abstract}

The Mn rich $\mathrm{Ni}_{50} \mathrm{Mn}_{50-x} \mathrm{Z}_{x}(\mathrm{Z}=\mathrm{In}, \mathrm{Sb}, \mathrm{Sn})$ based Heusler alloys have gained significant interest in recent years due to their rich fundamental physics and potential as multifunctional materials. ${ }^{1-5}$ The multifunctional properties of these alloys include large magnetocaloric effects, ${ }^{2,6,7}$ giant magnetoresistance, ${ }^{8}$ magnetic shape memory effects, ${ }^{9}$ barocaloric effects, ${ }^{10}$ and exchange bias effects. ${ }^{11,12}$ Most of these exciting properties are associated with the coupled magnetocrystalline martensitic phase transition during which the high temperature cubic L2 1 phase (austenite) of the alloys transforms to a low temperature phase (martensite) with a lower symmetry. The structure of the martensite is composition dependent and may be orthorhombic or monoclinic. ${ }^{1,3,13}$ Both antiferromagnetic and ferromagnetic correlations play important roles in the magnetism of the martensitic phase, whereas the austenite exhibits ferromagnetic correlations. ${ }^{14}$

In $\mathrm{Ni}_{50} \mathrm{Mn}_{50-x} \mathrm{Z}_{x}$ alloys, the martensitic transition temperature, $\mathrm{T}_{M}$, is generally believed to be dependent on the valence electron concentration, e/a. $\mathrm{T}_{M}$ generally increases (decreases) with increasing (decreasing) $e / a .{ }^{13}$ However, in recent literature a few observations have been reported where $\mathrm{T}_{M}$ was found to depend non-monotonically on $e / a$. For example, when $\mathrm{Mn}$ is replaced by $\mathrm{Cu}$ in $\mathrm{Ni}_{50} \mathrm{Mn}_{35-x} \mathrm{Cu}_{x} \mathrm{Sn}_{15}, \mathrm{~T}_{M}$ first increases and then decreases rapidly with increasing $\mathrm{Cu}$ concentration (increasing $e / a) .{ }^{15}$ In the case where $\mathrm{Mn}$ is replaced by $\mathrm{Fe}$ in $\mathrm{Ni}_{50} \mathrm{Mn}_{38-x} \mathrm{Fe}_{x} \mathrm{Sb}_{12}$ and $\mathrm{Ni}_{50} \mathrm{Mn}_{36-x} \mathrm{Fe}_{x} \mathrm{Sn}_{14}$, a monotonic decrease of $\mathrm{T}_{M}$ with increasing $e / a$ is observed. ${ }^{16,17}$ These observations, along with several others ${ }^{18}$ suggest that, regardless of the e/a concentration, $\mathrm{T}_{M}$ decreases and eventually disappears when $\mathrm{Ni}$ or $\mathrm{Mn}$ is partially replaced by another transition metal in the $\mathrm{Ni}_{50} \mathrm{Mn}_{50-x} \mathrm{Z}_{x}$ alloys.

Ye et al. recently investigated the temperature dependence of the electronic structures of $\mathrm{Ni}_{2} \mathrm{Mn}_{1+x} \mathrm{Sn}_{1-x}$ by means of bulk-sensitive, hard-x-ray photoelectron spectroscopy and ab initio calculations. ${ }^{19}$ According to this study, the Ni-Mn hybridization is the main driving force for the martensitic transformation in Mn-rich Ni-Mn-Z alloys. In this case, once the hybridization is established, any change in the $\mathrm{Ni}$ or $\mathrm{Mn}$ concentration will weaken the hybridization, leading to the disappearance of the martensitic transformation and stabilization of the $\mathrm{L} 2{ }_{1}$ structure. This implies that $e / a$ will have a minimal role (if any) on the stabilization of the martensitic phase.

Although a few studies (as mentioned above) indicate that this is the case, in order to confirm that Ni-Mn hybridization is the main factor that determines the stabilization of the martensitic phases rather than $e / a$, a more systematic study is needed, where $e / a$ is varied in the same parent compound. Therefore, we have performed a systematic experimental study on a series of $\mathrm{Ni}_{50} \mathrm{Mn}_{37-x} \mathrm{Cr}_{x} \mathrm{Sb}_{13}$ and $\mathrm{Ni}_{50+x} \mathrm{Mn}_{37-x} \mathrm{Sb}_{13}$ alloys by using dc magnetization and $\mathrm{ac}$ susceptibility measurements. The strategy was to observe the change in $\mathrm{T}_{M}$ with increasing and decreasing $e / a$ while using the same $\left(\mathrm{Ni}_{50} \mathrm{Mn}_{37} \mathrm{Sb}_{13}\right)$ parent compound in both alloy systems. In the case of $\mathrm{Ni}_{50} \mathrm{Mn}_{37-x} \mathrm{Cr}_{x} \mathrm{Sb}_{13}$, ela decreases with increasing $\mathrm{Cr}$ concentration, while ela increases with increasing $\mathrm{Ni}$ concentration in $\mathrm{Ni}_{50+x} \mathrm{Mn}_{37-x} \mathrm{Sb}_{13}$ alloys. In both cases, the Mn content was reduced in a similar fashion. This strategy allowed us to observe the change in $\mathrm{T}_{M}$ as a function of both Mn content and e/a.

The $\mathrm{Ni}, \mathrm{Mn}, \mathrm{Cr}$, and $\mathrm{Sb}$ metals used in preparing the alloys were obtained from Alfa Aesar Inc. and were of $4 \mathrm{~N}$ purity. Approximately $2 \mathrm{~g}$ polycrystalline buttons of each alloy were prepared by conventional arc-melting in an argon atmosphere. The weight loss after melting was found to be less than $0.3 \%$. For homogenization, the samples were annealed in vacuum for $72 \mathrm{~h}$ at $850^{\circ} \mathrm{C}$, followed by quenching in cold water. The $e / a$ was calculated from the chemical formula of the compound; it is equal to the concentration weighted sum of the number of $3 \mathrm{~d}$ and $4 \mathrm{~s}$ electrons of $\mathrm{Ni}$ 


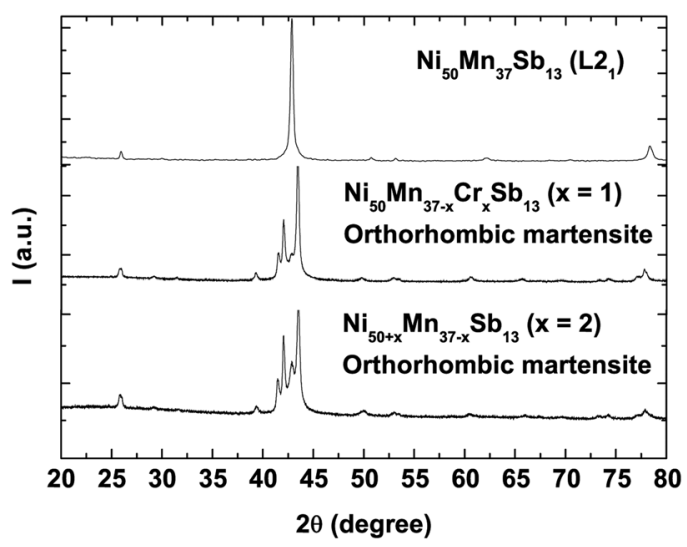

FIG. 1. Room temperature XRD patterns of selected alloys.

$\left(3 d^{8} 4 s^{2}\right)$, Mn $\left(3 d^{5} 4 s^{2}\right)$, and $\mathrm{Cr}\left(3 d^{5} 4 s^{1}\right)$ and the number of $5 s$ and $5 p$ electrons of $\mathrm{Sb}\left(5 \mathrm{~s}^{2} 5 \mathrm{p}^{3}\right) .{ }^{1,18,20}$ The structural properties of the alloys have been checked by performing room temperature $\mathrm{x}$-ray powder diffraction (XRD) on a Rigaku diffractometer employing monochromatic $\mathrm{Cu} \mathrm{K} \alpha_{1}$ radiation. The crystal structure and the lattice parameters were determined by performing Reitveld refinement using LHPM-RIETICA. ${ }^{21}$ The ac susceptibility measurements were conducted in a homemade ac susceptibility setup in zero dc magnetic field. The magnetization measurements were performed in a superconducting quantum interference device SQUID manufactured by Quantum Design, Inc. The measurements were performed in a temperature range of $10-400 \mathrm{~K}$ and in a magnetic field of $100 \mathrm{Oe}$.

Figure 1 shows illustrative room temperature XRD patterns for $\mathrm{Ni}_{50} \mathrm{Mn}_{37} \mathrm{Sb}_{13}, \mathrm{Ni}_{50} \mathrm{Mn}_{37-x} \mathrm{Cr}_{x} \mathrm{Sb}_{13} \quad(x=2)$, and $\mathrm{Ni}_{50+x} \mathrm{Mn}_{37-x} \mathrm{Sb}_{13}(x=1)$. The parent alloy $\left(\mathrm{Ni}_{50} \mathrm{Mn}_{37} \mathrm{Sb}_{13}\right)$ exhibits the cubic L2 1 structure at room temperature. As Mn is partially replaced by either $\mathrm{Cr}$ or $\mathrm{Ni}$, the $\mathrm{L} 2{ }_{1}$ structure transforms to the 40 modulated orthorhombic structure. ${ }^{22}$ As $x$ exceeds 2 , the $\mathrm{L} 2{ }_{1}$ cubic structure is restored and preserved for alloys with larger values of $x$.

Figure 2 shows the magnetization as a function of increasing temperature, $\mathrm{M}(\mathrm{T})$, of the $\mathrm{Ni}_{50} \mathrm{Mn}_{37-x} \mathrm{Cr}_{x} \mathrm{Sb}_{13}$ alloys measured at a magnetic field of $100 \mathrm{Oe}$. Before the zero-field-cooled (ZFC) measurement, the sample was cooled down from room temperature to $10 \mathrm{~K}$ in zero magnetic field. In case of the field-cooled heating $(\mathrm{FCH})$ measurement, the sample was cooled to $10 \mathrm{~K}$ in the presence of a 100 Oe magnetic field. The ZFC M(T) data of the alloy with $x=0$ exhibit three transitions (see Fig. 2(a)) that are typically observed in these alloys. ${ }^{4,5}$ The exchange bias blocking temperature, $\mathrm{T}_{E B}$, was observed at $74 \mathrm{~K}$ followed by $\mathrm{T}_{M}$ at $293 \mathrm{~K}$, and the ferromagnetic transition temperature of the austenitic phase, $\mathrm{T}_{C}^{A}$ at $342 \mathrm{~K}$. As usual, due to pinning effects, $\mathrm{T}_{E B}$, was only observed in the $\mathrm{ZFC} \mathrm{M(T)} \mathrm{data.} \mathrm{As}$ $\mathrm{Mn}$ is initially replaced by a small amount of $\mathrm{Cr}(x=1)$, an additional transition (ferromagnetic transition temperature, $\mathrm{T}_{C}^{M}$, of the martensitic phase) is observed in the alloy, while $\mathrm{T}_{M}$ shifted to higher temperature. It is interesting to note that the transition at $\mathrm{T}_{C}^{M}$, and the increase of $\mathrm{T}_{M}$, were only observed in the alloys with $x=1$ and 2 . With a further increase of $\mathrm{Cr}$ concentration, $\mathrm{T}_{M}$ decreases rapidly and disappears as $x$ exceeds 5 . As shown in the ac susceptibility data in Fig. 3, similar behavior was observed when Mn was partially replaced with $\mathrm{Ni}$ in $\mathrm{Ni}_{50+x} \mathrm{Mn}_{37-x} \mathrm{Sb}_{13} . \mathrm{T}_{C}^{M}$ is only observed in the alloys with $x=1$ and 2 , while $\mathrm{T}_{M}$ initially increases with increasing $\mathrm{Ni}$ concentration, and then decreases rapidly upon further increase of Ni. Since we are primarily interested in the transition temperatures $\mathrm{T}_{M}, \mathrm{~T}_{C}^{M}$, and $\mathrm{T}_{C}^{A}$, only ac susceptibility measurements were conducted on the $\mathrm{Ni}_{50+x} \mathrm{Mn}_{37-x} \mathrm{Sb}_{13}$ samples.

In Fig. 4 the transition temperatures, $\mathrm{T}_{M}, \mathrm{~T}_{C}^{M}$, and $\mathrm{T}_{C}^{A}$ of the $\mathrm{Ni}_{50} \mathrm{Mn}_{37-x} \mathrm{Cr}_{x} \mathrm{Sb}_{13}$ and $\mathrm{Ni}_{50+x} \mathrm{Mn}_{37-x} \mathrm{Sb}_{13}$ alloys are
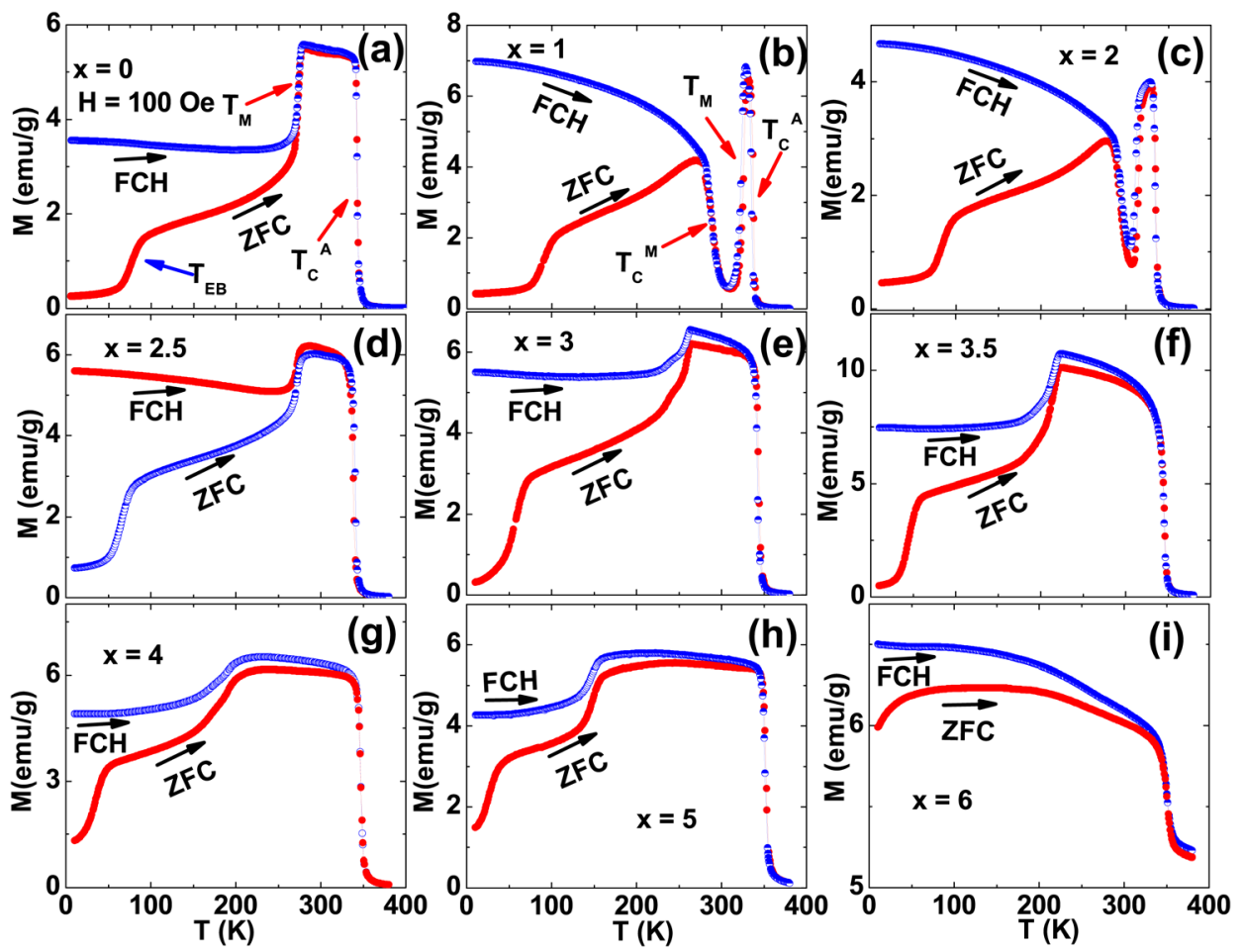

FIG. 2. Magnetization as a function of increasing temperature of $\mathrm{Ni}_{50} \mathrm{Mn}_{37-x} \mathrm{Cr}_{x}$ $\mathrm{Sb}_{13}$ alloys measured at a magnetic field of $100 \mathrm{Oe}$. 

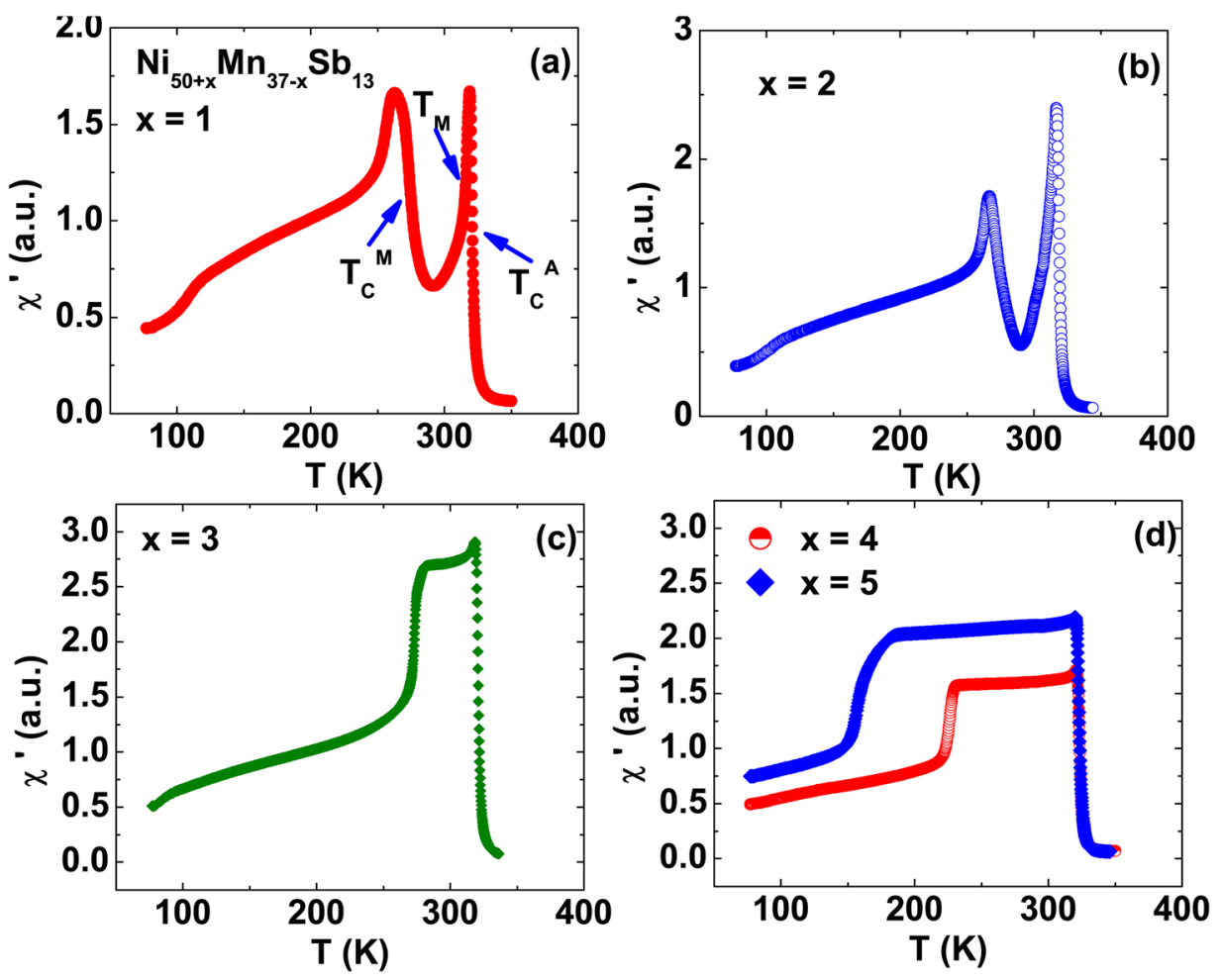

FIG. 3. The real component of the ac susceptibility of $\mathrm{Ni}_{50+x} \mathrm{Mn}_{37-x} \mathrm{Sb}_{13}$ alloys. plotted as a function of $e / a$. As mentioned earlier, with increasing $\mathrm{Cr}$ concentration, $e / a$ decreases in the $\mathrm{Ni}_{50} \mathrm{Mn}_{37-x} \mathrm{Cr}_{x} \mathrm{Sb}_{13}$ system, while $e / a$ increases with increasing $\mathrm{Ni}$ concentration in $\mathrm{Ni}_{50+x} \mathrm{Mn}_{37-x} \mathrm{Sb}_{13}$. For each system, $\mathrm{T}_{C}^{M}$ was observed only in two alloys, and hence a proper discussion of their dependence on ela cannot be made. $\mathrm{T}_{C}^{A}$ shows a generally slowly decreasing trend with increasing $e$ / $a$. This behavior is consistent with earlier observations where $\mathrm{T}_{C}^{A}$ slowly decreases with increasing $e / a .^{5}$ The most interesting behavior observed in Fig. 4 is the nature of the variation of $\mathrm{T}_{M}$ with ela. It is clear that, regardless of the change in $e /$ $a, \mathrm{~T}_{M}$ decreases with decreasing Mn concentration.

Ye et al. ${ }^{19}$ investigated the correlation between the electronic structure and martensitic phase transition of $\mathrm{Ni}_{2} \mathrm{Mn}_{1+x} \mathrm{Sn}_{1-x}$ by hard $\mathrm{x}$-ray photoelectron spectroscopy

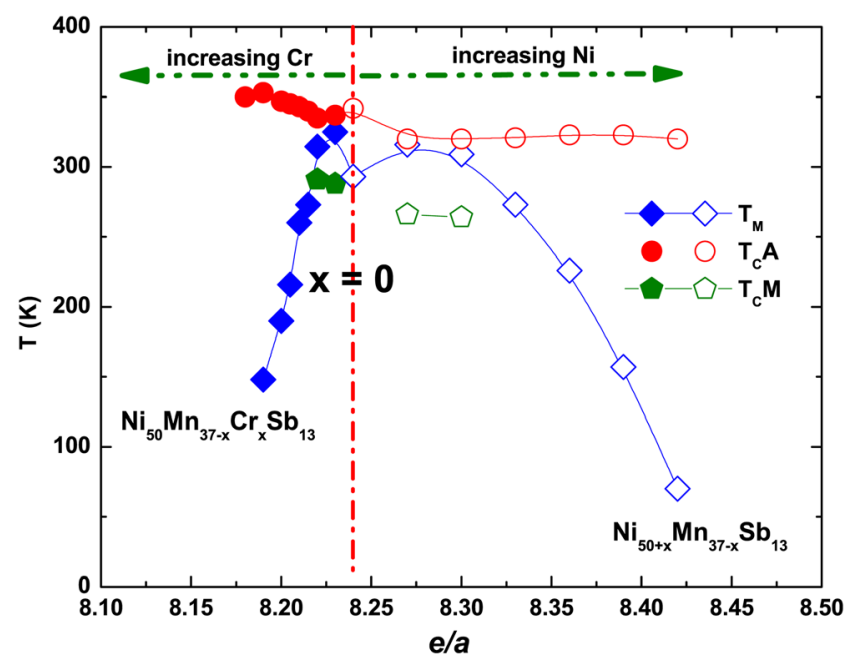

FIG. 4. The transition temperatures as a function of $e / a$ of $\mathrm{Ni}_{50} \mathrm{Mn}_{37-x} \mathrm{Cr}_{x} \mathrm{Sb}_{13}$ and $\mathrm{Ni}_{50+x} \mathrm{Mn}_{37-x} \mathrm{Sb}_{13}$ alloys. and $a b$ initio calculation. In their study, they discovered that a strong hybridization takes place between the $\mathrm{Ni} 3 \mathrm{~d} e_{g}$ states and the $3 \mathrm{~d}$ states of the excess $\mathrm{Mn}$ atoms at the $\mathrm{Sn}$ sites, which are antiferromagnetically coupled with the Mn on the regular site. This hybridization is believed to be the main reason causing the martensitic transition in $\mathrm{Ni}_{2} \mathrm{Mn}_{1+x} \mathrm{Sn}_{1-x}$. The role of hybridization in driving the martensitic phase transition in Heusler alloys was also demonstrated by Roy et al. ${ }^{23}$ who showed by various experimental means that partial replacement of $\mathrm{Mn}$ by $\mathrm{Cu}$ in $\mathrm{Ni}_{2} \mathrm{Mn}_{0.75} \mathrm{Cu}_{0.25} \mathrm{Ga}$ enhanced the Ni-Ga hybridization resulting in a shift of $\mathrm{T}_{M}$ to higher temperature. In light of these studies, especially the observations by Ye et al., we propose that the main driving force behind the martensitic transformation in Mn-rich Heusler alloys is the hybridization between the $\mathrm{Ni} 3 \mathrm{~d} e_{g}$ states and the $3 \mathrm{~d}$ states of the excess $\mathrm{Mn}$ atoms at the Sn sites. In such a scenario, once the hybridization is established, any change in the $\mathrm{Ni}$ or Mn content will tend to weaken the hybridization, and result in a decrease of $\mathrm{T}_{M}$. This idea is strongly supported by the results shown in Fig. 4 as well as by the results reported earlier where, regardless of the change in $e / a, \mathrm{~T}_{M}$ in Mn-rich Ni-Mn-Z Heusler alloys decreases when $\mathrm{Ni}$ or $\mathrm{Mn}$ is partially replaced by a different element. Based on these observations, it can be concluded that the widely accepted idea that $\mathrm{T}_{M}$ monotonically follows $e / a$ does not apply to Mn-rich Heusler alloys.

In summary, we have performed an experimental study on $\mathrm{Ni}_{50} \mathrm{Mn}_{37-x} \mathrm{Cr}_{x} \mathrm{Sb}_{13}$ and $\mathrm{Ni}_{50+x} \mathrm{Mn}_{37-x} \mathrm{Sb}_{13}$ Heusler alloys. With increasing $\mathrm{Cr}$ concentration $e / a$ decreases in $\mathrm{Ni}_{50} \mathrm{Mn}_{37-x} \mathrm{Cr}_{x} \mathrm{Sb}_{13}$, whereas $e / a$ increases with increasing $\mathrm{Ni}$ concentration in $\mathrm{Ni}_{50+x} \mathrm{Mn}_{37-x} \mathrm{Sb}_{13}$. Regardless of the change in $e / a$, in both cases $\mathrm{T}_{M}$ decreases with increasing $\mathrm{Cr}$ or $\mathrm{Ni}$ concentration, suggesting that the well developed idea of $\mathrm{T}_{M}$ monotonically following e/a does not apply to Mnrich Heusler alloys. We suggest that the dominant factor, 
which affects the behavior of the martensitic transition is the nature of hybridization between the $\mathrm{Ni} 3 \mathrm{~d} e_{g}$ states and the $3 \mathrm{~d}$ states of the excess $\mathrm{Mn}$ atoms at the $\mathrm{Sn}$ sites, which are antiferromagnetically coupled.

This work was supported by the Natural Sciences and Engineering Research Council of Canada. The authors also acknowledge the support of the Killam Trusts at the University of Alberta. The part of the work conducted at Southern Illinois University was supported by the Office of Basic Energy Sciences, Material Science Division of the U.S. Department of Energy (Grant No. DE-FG02-06ER46291).

${ }^{1}$ T. Krenke, M. Acet, E. F. Wassermann, X. Moya, L. Maosa, and A. Planes, Phys. Rev. B 72, 014412 (2005).

${ }^{2}$ T. Krenke, M. Acet, E. F. Wassermann, X. Moya, L. Maosa, and A. Planes, Nat. Mater. 4, 450 (2005).

${ }^{3}$ T. Krenke, M. Acet, E. F. Wassermann, X. Moya, L. Maosa, and A. Planes, Phys. Rev. B 73, 174413 (2006).

${ }^{4}$ M. Khan, I. Dubenko, S. Stadler and N. Ali, J. Phys. Condens. Matter 20, 235204 (2008).

${ }^{5}$ A. Planes, L. Manosa, and M. Acet, J. Phys.: Condens. Matter 21, 233201 (2009).

${ }^{6}$ M. Khan, N. Ali, and S. Stadler, J. Appl. Phys. 101, 053919 (2007).

${ }^{7}$ S. Stadler, M. Khan, J. Mitchell, N. Ali, A. M. Gomes, I. Dubenko, A. Y. Takeuchi, and A. P. Guimares, Appl. Phys. Lett. 88, 192511 (2006).

${ }^{8}$ A. K. Pathak, I. Dubenko, C. Pueblo, S. Stadler, and N. Ali, Appl. Phys. Lett. 96, 172503 (2010).

${ }^{9}$ R. Kainuma, Y. Imano, W. Ito, Y. Sutou, H. Morito, S. Okamoto, O. Kitakami, K. Oikawa, A. Fujita, T. Kanomata, and K. Ishida, Nature (London) 493, 957 (2006).
${ }^{10}$ L. Maosa, D. Gonzlez-Alonso, A. Planes, E. Bonnot, M. Barrio, J. L. Tamarit, S. Aksoy, and M. Acet, Nature Mater. 9, 478 (2010).

${ }^{11}$ M. Khan, I. Dubenko, S. Stadler, and N. Ali, Appl. Phys. Lett. 91, 072510 (2007).

${ }^{12}$ B. M. Wang, Y. Liu, P. Ren, B. Xia, K. B. Ruan, J. B. Yi, J. Ding, X. G. Li, and L. Wang, Phys. Rev. Lett. 106, 077203 (2011).

${ }^{13}$ S. Aksoy, M. Acet, E. F. Wassermann, T. Krenke, X. Moya, L. Maosa, A. Planes, and P. P. Deen, Philos. Mag. 89, 2093 (2009).

${ }^{14}$ S. Aksoy, M. Acet, P. P. Deen, L. Maosa, and A. Planes, Phys. Rev. B 79, 212401 (2009).

${ }^{15}$ B. Gao, J. Shen, F. X. Hu, J. Wang, J. R. Sun, and B. G. Shen, Appl. Phys. A 97, 443 (2009).

${ }^{16}$ E. C. Passamani, F. Xavier, E. Favre-Nicolin, C. Larica, A. Y. Takeuchi, I. L. Castro, and J. R. Proveti, J. Appl. Phys. 105, 033919 (2009).

${ }^{17}$ R. Sahoo, A. K. Nayak, K. G. Suresh, and A. K. Nigam, J. Appl. Phys. 109, 123904 (2011).

${ }^{18}$ W. J. Feng, L. Zuo, W. B. Li, Y. D. Wang, M. Gao, and G. L. Fang, Mater. Sci. Eng., B 176, 621 (2011).

${ }^{19}$ M. Ye, A. Kimura, Y. Miura, M. Shirai, Y. T. Cui, K. Shimada, H. Namatame, M. Taniguchi, S. Ueda, K. Kobayashi, R. Kainuma, T. Shishido, K. Fukushima, and T. Kanomata, Phys. Rev. Lett. 104, 176401 (2010).

${ }^{20}$ For example, the formula for calculating $e / a$ for the parent compound, $\mathrm{Ni}_{50} \mathrm{Mn}_{37} \mathrm{Sb}_{13}$ is

$$
e / a=\frac{50 \times 10+37 \times 7+13 \times 5}{50+37+13}=8.24
$$

${ }^{21}$ B. Hunter, Rietica-A Visual Rietveld Program, International Union of Crystallography Commission on Powder Diffraction Newsletter No. 20 (Summer, 1998), http://www.rietica.org.

${ }^{22}$ N. V. Rama Rao, R. Gopalan, V. Chandrasekaran, and K. G. Suresh, J. Phys. D: Appl. Phys. 42, 065002 (2009).

${ }^{23}$ S. Roy, E. Blackburn, S. M. Valvidares, M. R. Fitzsimmons, S. C. Vogel, M. Khan, I. Dubenko, S. Stadler, N. Ali, S. K. Sinha, and J. B. Kortright, Phys. Rev. B 79, 235127 (2009). 